\title{
Absence of scale dependence in dolphin-habitat models for the eastern tropical Pacific Ocean
}

\author{
J. V. Redfern*, J. Barlow, L. T. Ballance, T. Gerrodette, E. A. Becker \\ Southwest Fisheries Science Center, 8604 La Jolla Shores Drive, La Jolla, California 92037, USA
}

\begin{abstract}
Research into the effects of scale on cetacean-habitat relationships is limited and has produced ambiguous results. We explored the effects of spatial resolution (a component of scale) on dolphinhabitat models using $4 \mathrm{yr}$ of data collected in the eastern tropical Pacific Ocean (ETP). We developed generalized additive models of dolphin-habitat relationships for 4 species at 6 spatial resolutions using oceanographic and geographic habitat variables. For all species, the ecological patterns in the models built at the different resolutions were similar: the same variables frequently occurred at multiple resolutions and had similar functional forms, and maps of predicted distributions identified similar high and low density regions. Additionally, interannual habitat variability, which is most likely related to the El Niño-Southern Oscillation, had a greater impact on the predictive power of dolphin-habitat models than spatial resolution. Although it is common to find scale dependence in species-habitat relationships, domains of scale exist in which ecological patterns do not change. The absence of scale dependence in the models for the 4 dolphin species suggests that resolutions from 2 to $120 \mathrm{~km}$ occur within a single domain of scale in the ETP. This domain of scale may be determined by the physical oceanography of the ETP, which is generally defined by large-scale processes. Although resolutions from 2 to $120 \mathrm{~km}$ appear to occur within a domain of scale, building models at the larger resolutions we investigated may reduce the noise in the data due to false absences.
\end{abstract}

KEY WORDS: Dolphin density - Habitat modeling Striped dolphin - Stenella coeruleoalba - Eastern spinner dolphin - Stenella longirostris orientalis . Short-beaked common dolphin - Delphinus delphis . Risso's dolphin · Grampus griseus

Resale or republication not permitted without written consent of the publisher

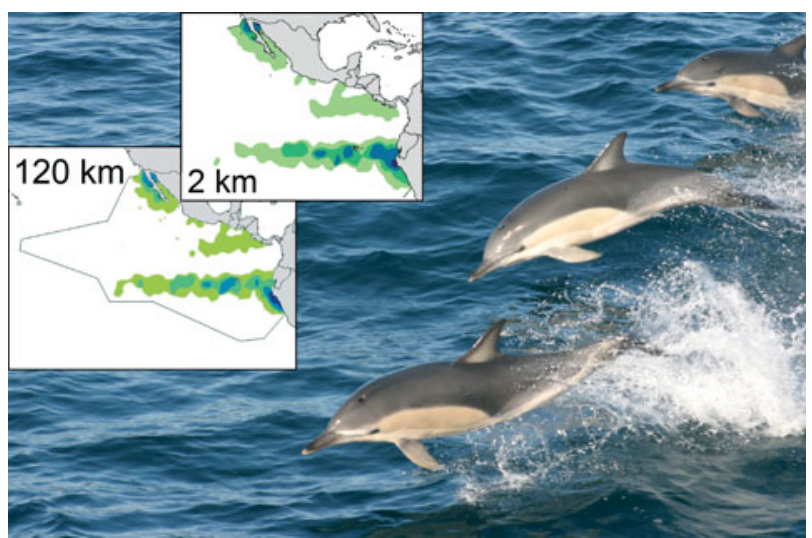

Modeled densities indicate scale-independence in dolphinhabitat relationships

Image: J.V. Redfern

\section{INTRODUCTION}

The influence of scale on the identification and interpretation of ecological patterns has long been a central theme in ecological research (Haury et al. 1978, Wiens 1989, Levin 1992). Of particular importance is spatial scale dependence in species-habitat relationships, which has been documented for a variety of seabird species (e.g. Logerwell \& Hargreaves 1996, Logerwell et al. 1998, Fauchald et al. 2000, Davoren et al. 2002, Pinaud \& Weimerskirch 2005). For example, seabird studies suggest that the strength of the correlation between seabirds and prey generally increases with increasing spatial resolution (Schneider \& Piatt 1986, Heinemann et al. 1989, Erikstad et al. 1990, Piatt 1990, Hunt 1991, Hunt et al. 1992, Logerwell \& Hargreaves 1996, Fauchald et al. 2000), although there are exceptions (e.g. Cairns \& Schneider 1990). 
Research into the effects of scale on cetacean-habitat relationships is more limited and has produced ambiguous results. Jaquet \& Whitehead (1996) analyzed a range of resolutions (i.e. the unit of analysis, a component of scale) from 80 to 640 nautical miles (n mile) (148 to $1185 \mathrm{~km}$ ) and found that sperm whale density in the South Pacific was correlated with habitat variables only at resolutions greater than $320 \mathrm{n}$ mile (593 km). Hamazaki (2002) assessed the effect of spatial resolutions ranging from $4 \times 4 \mathrm{~km}$ grid cells to $96 \times$ $96 \mathrm{~km}$ grid cells on predictive habitat models for 13 cetacean species in the mid-western North Atlantic Ocean and found no relationship between resolution and the correct classification rate of logistic regression models. While Hamazaki's (2002) results suggest that spatial resolution did not affect the predictive power of the models, ecological questions about the effect of resolution cannot be addressed because the behavior of the predictor variables at the different resolutions (e.g. the magnitude and sign of the relationship) was not examined.

We expect scale-dependent habitat relationships for cetaceans and seabirds because both are apex marine predators that must respond to the hierarchical patch structure of their prey in which high density, smallscale patches are nested within lower density, largescale patches (Murphy et al. 1988, Fauchald 1999, Fauchald et al. 2000). Heterogeneity, which may be a driving factor in scale-dependent species-habitat relationships (Wiens 1989), occurs at every stage of this hierarchy and is coupled with biological and physical processes (Haury et al. 1978). Heterogeneity in smallscale patches (100s of $\mathrm{m}$ ) may be driven by prey behavior or by turbulent diffusion and mixing for weakly swimming organisms; heterogeneity in mesoscale patches (10s to $100 \mathrm{~s}$ of $\mathrm{km}$ ) may be caused by oceanographic features such as fronts and eddies (Murphy et al. 1988, Fauchald 1999, Fauchald et al. 2000).

A primary difference between cetacean and seabird habitat studies is found in the variables used to define habitat. Cetacean habitat is often defined using oceanographic variables (Redfern et al. 2006), while seabird habitat is frequently defined using prey density. Cetacean studies may use variables such as sea surface temperature and salinity to represent physiological constraints or identify water masses typical of good prey habitat as well as variables such as thermocline depth and strength, which are expected to influence prey abundance or availability. Consequently, relationships between apex marine predators and habitat defined by oceanographic variables should be subject to scale dependencies because heterogeneity in prey patches is likely to be linked to oceanographic conditions.
In this paper, we explore the effects of spatial resolution on dolphin-habitat models using 4 yr of data collected aboard research vessels in the eastern tropical Pacific Ocean (ETP). We developed generalized additive models (GAMs) of dolphin-habitat relationships at 6 spatial resolutions by varying the unit of analysis from 2 to $120 \mathrm{~km}$. Habitat was defined using physical and biological oceanographic and geographic variables. Four dolphin species were selected to represent a range of habitat types and selectivity: striped dolphin Stenella coeruleoalba, eastern spinner dolphin $S$. longirostris orientalis, short-beaked common dolphin Delphinus delphis, and Risso's dolphin Grampus griseus.

\section{MATERIALS AND METHODS}

Study area and data collection. The ETP (Fig. 1) is a large (19.6 million $\mathrm{km}^{2}$ ), oceanographically diverse area that supports at least 29 cetacean species (Wade \& Gerrodette 1993). Temporal variability in the ETP exists at a range of scales, but is dominated by interannual variability created by the El Niño-Southern Oscillation (ENSO) (Fiedler 2002a). On a macroscale, the ETP is defined by 3 surface currents: the North Equatorial Current, the North Equatorial Countercurrent, and the South Equatorial Current (Fig. 1). The northern and southern regions of the ETP are defined by Subtropical Surface Water (Fig. 1), which has the highest salinity values (greater than 35) and lowest nutrient concentrations in the area (Fiedler \& Talley 2006). The central region is defined by Tropical Surface Water north of the equator, which includes the eastern Pacific warm pool, and by Equatorial Surface Water along the equator, which includes the equatorial cold tongue (Fig. 1). Tropical Surface Water has higher surface temperatures (greater than $25^{\circ} \mathrm{C}$ ), lower salinity values (less than 34 ), and lower nutrient concentrations than the Equatorial Surface Water (Fiedler \& Talley 2006). The eastern boundary currents (i.e. the California Current and the Peru Current) also have high nutrient concentrations relative to surrounding regions (Fiedler \& Talley 2006).

The ETP contains a number of mesoscale features that also define the habitat of this region (Fig. 1). Thermal fronts occur between the eastern boundary currents and the warm pool, as well as between the South Equatorial Current and the North Equatorial Countercurrent (Fiedler \& Talley 2006). The Equatorial Front, which occurs between the Peru Current and the North Equatorial Countercurrent, is one of the most prominent, low latitude, oceanic fronts in the world. It is a permanent feature of the region, although its intensity varies both spatially and temporally. A strong, shallow 


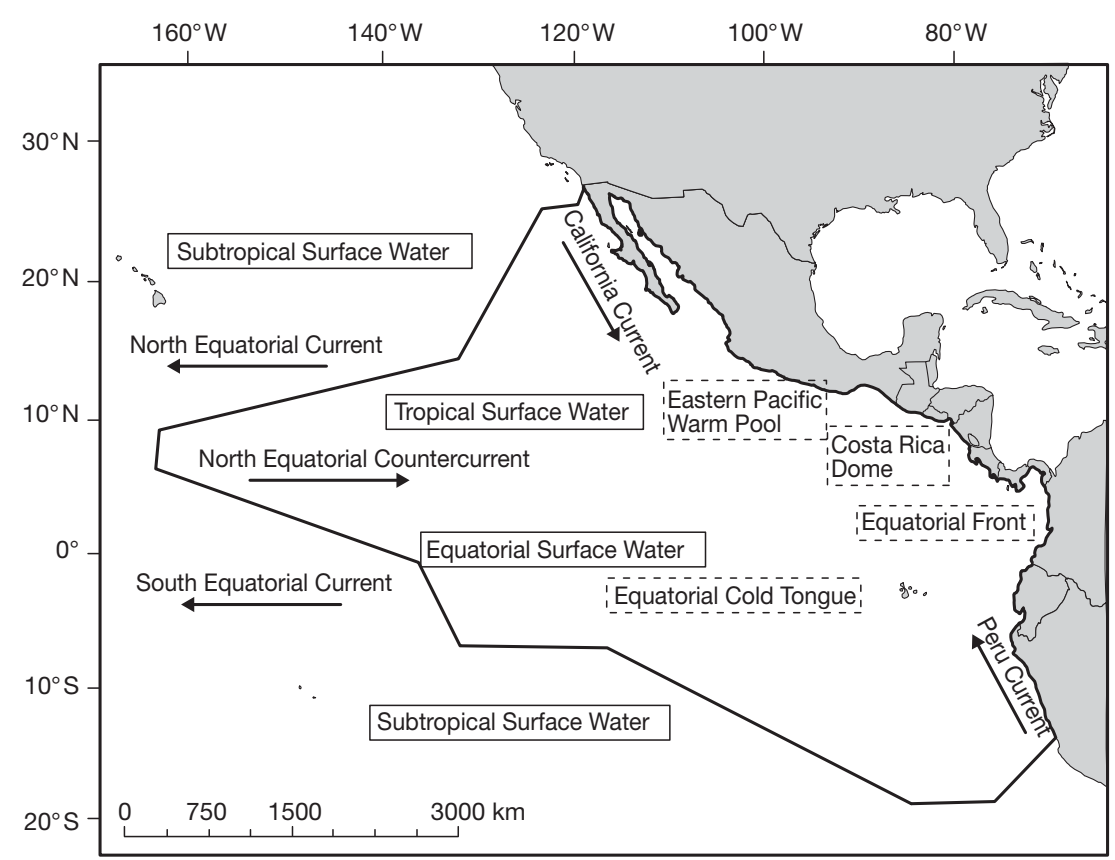

Fig. 1. Primary oceanographic features in the eastern tropical Pacific Ocean (ETP) that influence dolphin habitats. Study area is shown by the thick black line; water masses are identified by solid boxes; currents are shown with an arrow indicating the direction of flow, and other important features are identified by dashed boxes (adapted from Wyrtki 1966, 1967, Fiedler \& Talley 2006)
Guatemala to Colombia. Dolphin data were collected during daylight hours using line-transect methods (Buckland et al. 2001); field protocols are described in detail in Kinzey et al. (2000), Barlow et al. (2001), and Gerrodette \& Forcada (2005). We used approximately $70000 \mathrm{~km}$ of oneffort sampling data, which is defined as sampling conducted by the full observing team when Beaufort sea state was less than 6 . The transects provided dense coverage of the study area (Fig. 2). Survey effort consisted of 2 observers searching for dolphins from the flying bridge of the ship (at a height ranging between 10 and $15 \mathrm{~m}$ above sea level) using pedestalmounted $25 \times 150$ binoculars. A third observer served as the data recorder and searched by naked eye or with $7 \times$ handheld binoculars. Observers also regularly recorded survey conditions, including the Beaufort sea state. When dolphins were detected, the vessel approached the group as needed to identify the species and obtain group size estimates. Observers independently recorded their best thermocline predominates throughout the ETP, and a thermocline ridge predictably occurs between the North Equatorial Current and the North Equatorial Countercurrent. The Costa Rica Dome, a cyclonic gyre that develops at the eastern end of this ridge, is an area of regionally high surface chlorophyll from May to September (Fiedler 2002b). High productivity in the dome is supported by nutrients brought to the surface by wind mixing and upwelling. These 3 features, the Equatorial Front, the thermocline ridge, and the Costa Rica Dome, are significant for a number of seabirds and cetaceans (Ballance et al. 2006).

We used spatially referenced dolphin and oceanographic data that were collected by the Southwest Fisheries Science Center (NOAA Fisheries). The data were collected from 2 comparable oceanographic research vessels from late July until early December in 1992 and 1998 to 2000 (a third comparable vessel was also used in 1998). The 1992 survey focused on a subsection of the study area off the Middle and South American coast from

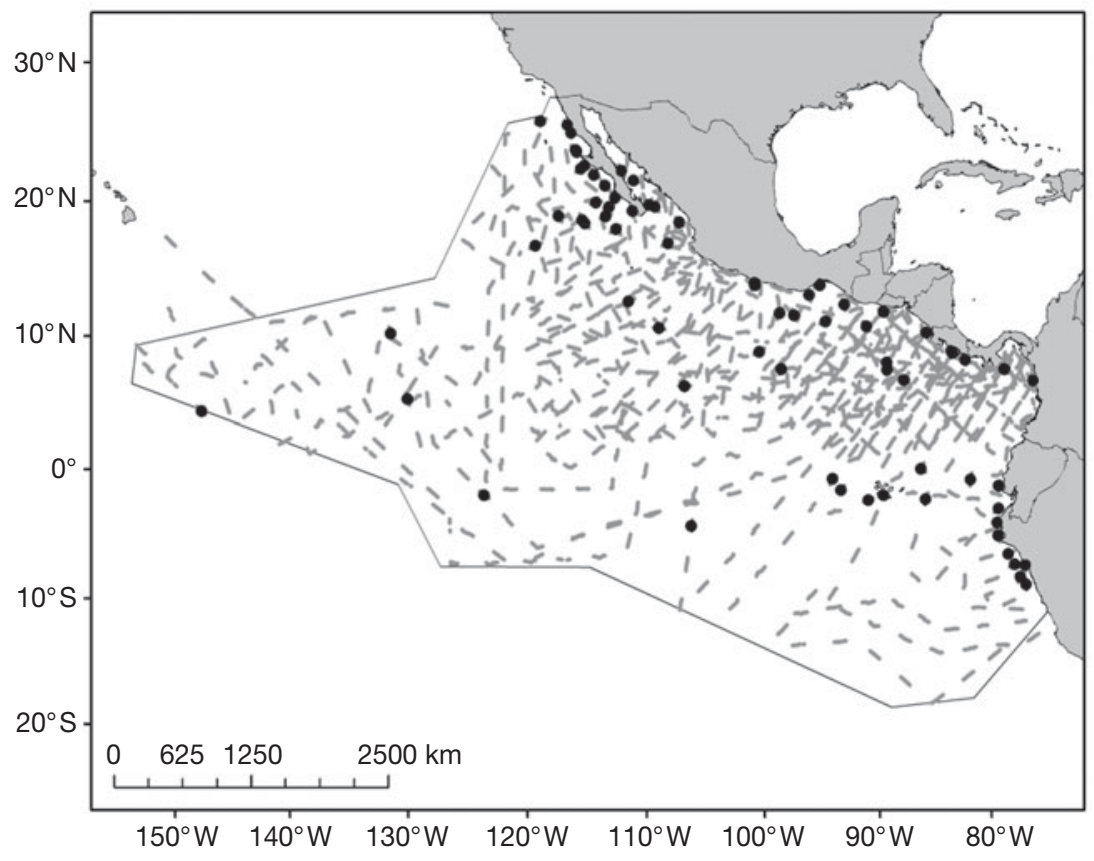

Fig. 2. Transect lines (- - - -) used to collect dolphin and oceanographic data in the ETP. Data were collected aboard 2 research vessels from late July until early December in 1992 and 1998 to 2000 (3 vessels were used in 1998). Locations of the largest $10 \%$ of temperature fronts at the $120 \mathrm{~km}$ resolution are shown for all years of data $(\bullet)$. Fronts were defined as the difference between the minimum and maximum temperature recorded on a segment 
estimate of group size, as well as high and low group size estimates, for each sighting. To obtain a single group size estimate for each sighting, we averaged the best estimate from each observer. In mixed species sightings, we averaged the estimates of the percentage of each species from each observer. We used only oneffort sightings that were identified to species in our analyses. Additionally, only those sightings for which at least 1 observer estimated a best group size and (where applicable) species percentages were included in our analyses.

Oceanographic sampling was systematically conducted during each survey (see Fiedler \& Philbrick 2002 for a detailed description). Surface temperature and salinity were recorded at 2 min intervals using a thermosalinograph. Surface chlorophyll concentrations were measured at approximately $55 \mathrm{~km}$ intervals using a fluorometer. Water column properties, including thermocline depth and strength (i.e. midpoint of the depth interval containing the maximum temperature gradient and the value of the gradient, respectively), were derived from data collected using expendable bathythermographs (XBTs) and CTD casts. XBT drops to $760 \mathrm{~m}$ were conducted at approximately $55 \mathrm{~km}$ intervals each day and CTD casts to $1000 \mathrm{~m}$ were conducted before sunrise and after sunset. The seafloor depth was derived from a digital bathymetric map with a resolution of 1 to $12 \mathrm{~km}$, which captures intermediate and large-scale structures of the ocean basins including canyons, ridges, and seamounts (Smith \& Sandwell 1997), using ARCGIS version 9.1 (ESRI).

Data analyses. The design of the ETP cetacean and ecosystem assessment surveys resulted in transects that traversed the study area and ran parallel to each other or intersected at multiple locations. Transects in close spatial proximity may be temporally separated such that oceanographic conditions differ substantially. Consequently, a gridded representation of our data would combine temporally separated transects and was therefore deemed too coarse to adequately represent concurrent dolphin-habitat relationships. Instead, we summarized the data in $2,10,20,40,60$, and $120 \mathrm{~km}$ segments along the transect lines; segment lengths were calculated using great circle distances from the starting point of effort each day. The $120 \mathrm{~km}$ resolution corresponds to a minimum amount of transect covered in a typical day; effort beyond $120 \mathrm{~km}$ was excluded from our analyses. The ship generally continued along the transect at night, producing a break in survey effort that is assumed to reduce dependence among daily segments. Consequently, we did not explore resolutions larger than $120 \mathrm{~km}$.

Four dolphin species were included in our analyses: striped dolphin, eastern spinner dolphin, short-beaked common dolphin, and Risso's dolphin. Encounter rate and group size models were built for each species. Dolphin encounter rates were calculated as the number of sightings of each species on a segment divided by the distance traveled on effort in that segment. When more than one sighting of a given species occurred on a segment, group sizes were averaged to obtain a single group size. We did not assess spatial autocorrelation in our dependent dolphin variables because we were concerned with the predictive power of the models, which is not affected by spatial autocorrelation.

Habitat variables used in our analyses were surface temperature and salinity, the natural logarithm of surface chlorophyll concentration (this transformation was used because the minimum and maximum measured values differed by more than an order of magnitude), thermocline depth and strength, and seafloor depth. We also approximated temperature fronts by subtracting the minimum from the maximum temperature on each segment. Large temperature differences tended to occur along the Equatorial Cold Tongue and in the coastal waters of our study area (Fig. 2). We also included Beaufort sea state as a predictor variable in our models. Although Beaufort sea state is not expected to affect the number or type of dolphins on a segment, it was included as a correction for sighting conditions because the probability of detecting dolphins decreases with increasing Beaufort sea states (Barlow et al. 2001). The product-moment correlation coefficients among all pairs of variables at the $2 \mathrm{~km}$ scale were between -0.5 and 0.5 .

Surface chlorophyll concentration and thermocline depth and strength were interpolated to the midpoint of the $2 \mathrm{~km}$ segments using inverse distance weighting; the degree of smoothing for each of these variables depended on the frequency of data collection (Fig. 3). Only 2 oceanographic measurements, the one temporally before and the one temporally after the segment midpoint, were used in the interpolation. Segments were not used in analyses unless both measurements were within $370.4 \mathrm{~km}$ (approximately $200 \mathrm{n}$ mile) of the midpoint. All surface temperature and salinity measurements made within a segment were averaged to obtain a single value. The seafloor depth was calculated at the midpoint of each $2 \mathrm{~km}$ segment. Mean Beaufort sea state values, weighted by the amount of on-effort distance traveled in that state, were also calculated for each $2 \mathrm{~km}$ segment. Only segments for which mean Beaufort sea state was $<5.5$ were included in our analyses because of the difficulty in detecting dolphins at higher Beaufort sea states.

Estimates of surface chlorophyll, thermocline depth and strength, seafloor depth, and Beaufort sea state for the $2 \mathrm{~km}$ segments were averaged to create the corresponding values for $10,20,40,60$, and $120 \mathrm{~km}$ seg- 

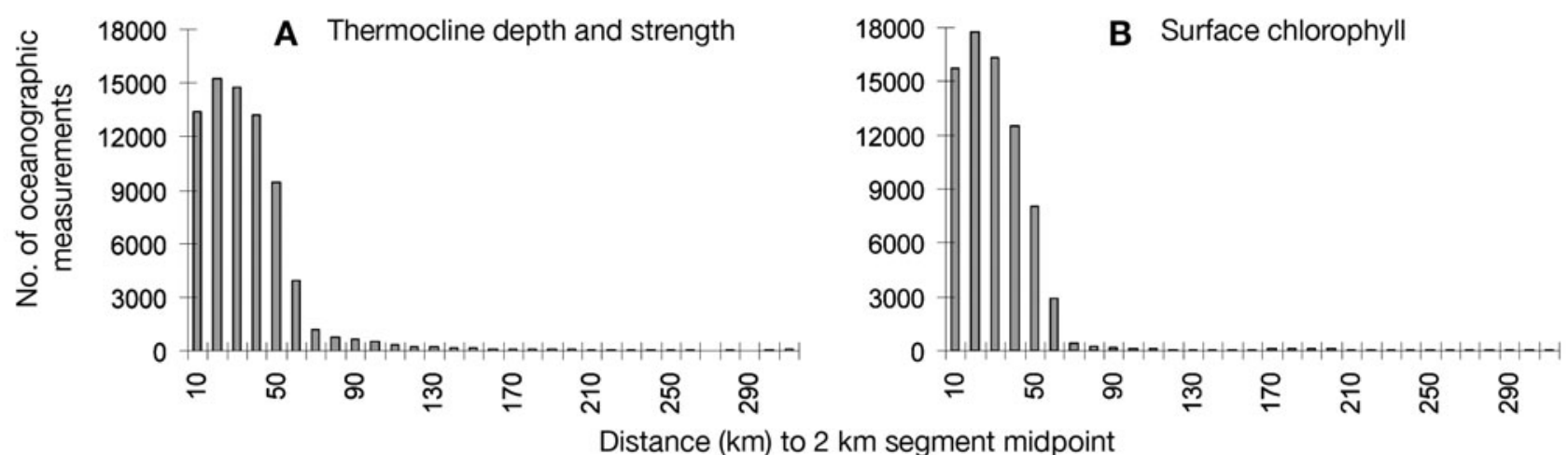

Fig. 3. Frequencies of the distances between the midpoints of the $2 \mathrm{~km}$ segments and the data collection locations used for the interpolation of (A) thermocline depth and strength and (B) surface chlorophyll measurements

ments. Temperature, salinity, and temperature front values were recalculated for each segment. Any larger segment containing one or more $2 \mathrm{~km}$ segments with a missing value for a predictor variable was also assigned a missing value. Because a single missing value at the $2 \mathrm{~km}$ resolution produces missing values at the larger resolutions, there are many days containing $2 \mathrm{~km}$ segments but no segments at the larger resolutions. To ensure consistency in the data across resolutions, only days for which the $120 \mathrm{~km}$ segment contained complete oceanographic data were used for all resolutions. The total number of segments, number of dolphin sightings, and mean dolphin group sizes for each resolution are presented in Table 1.

We used GAMs to explore the effects of spatial resolution on dolphin-habitat relationships in the ETP. A GAM approach was selected because it can fit a non-parametric relationship between the response and predictor variables via a scatterplot smoother; consequently, this approach allows the data to identify nonlinearities in dolphin-habitat relationships rather than imposing parametric fits through polynomial terms in a linear regression (Chambers \& Hastie 1991). This approach has been applied to model cetaceanhabitat relationships for delphinids (Ferguson et al. 2006a) and beaked whale species (Ferguson et al. 2006b) using data collected in the ETP from 1986 to 1990. The software package SPlus (Windows Professional Developer, version 7.0, Insightful Corp.) was used to fit the GAMs; we chose cubic smoothing splines (Hastie \& Tibshirani 1990) with a maximum of 3 degrees of freedom for all predictor variables to capture non-linear relationships, while limiting the inclusion of unrealistic detail in the shape of the function (Forney 2000).

Dolphin encounter rates are expected to follow an overdispersed Poisson distribution; therefore, encounter rate models were built using a logarithmic link and quasi-likelihood error distribution in which the variance was proportional to the mean. The distance traveled on effort for each segment was incorporated as an offset in the models. Dolphin group size models were fit using only those segments in which the species was present; models were built using a log-normal distribution. For both dolphin encounter rate and group size models, an automated forward/backward stepwise approach based on Akaike's information criterion (AIC) was used to select the variables for inclusion in each model as well as the degrees of freedom for the cubic smoothing splines (Ferguson et al. 2006a). Each model was fitted 3 times, starting with a null model that included only the intercept. The dispersion

Table 1. Number of sightings (Sight.) and mean group size (GS) are shown for the 4 species and 6 spatial resolutions (including total number of segments for each resolution) considered in our analyses. The $120 \mathrm{~km}$ resolution has the highest number of encounters for several species because segments with Beaufort sea state values $>5.5$ were excluded from our analyses. In particular, $2 \mathrm{~km}$ segments containing an encounter and occurring in Beaufort sea states $>5.5$ may not contribute to the analyses at the smaller resolutions but may contribute at the larger resolutions if the average Beaufort sea state on the longer segment was $\leq 5.5$. Striped dolphin Stenella coeruleoalba, eastern spinner dolphin $S$. longirostris orientalis, short-beaked common dolphin Delphinus delphis, Risso's dolphin Grampus griseus

\begin{tabular}{|c|c|c|c|c|c|c|c|c|c|}
\hline \multirow[t]{2}{*}{$\begin{array}{l}\text { Spatial } \\
\text { resolution } \\
(\mathrm{km})\end{array}$} & \multicolumn{2}{|c|}{$\begin{array}{l}\text { Striped } \\
\text { dolphin }\end{array}$} & \multicolumn{2}{|c|}{$\begin{array}{l}\text { Eastern } \\
\text { spinner } \\
\text { dolphin }\end{array}$} & \multicolumn{2}{|c|}{$\begin{array}{l}\text { Short-beaked } \\
\text { common } \\
\text { dolphin }\end{array}$} & \multicolumn{2}{|c|}{$\begin{array}{l}\text { Risso's } \\
\text { dolphin }\end{array}$} & \multirow[t]{2}{*}{$\begin{array}{c}\text { Total } \\
\text { no. of } \\
\text { segments }\end{array}$} \\
\hline & Sight. & GS & Sight. & GS & Sight. & GS & Sight. & GS & \\
\hline 2 & 420 & 49.03 & 161 & 96.87 & 263 & 160.93 & 134 & 21.46 & 37830 \\
\hline 10 & 420 & 49.09 & 161 & 96.76 & 263 & 162.35 & 134 & 21.23 & 8659 \\
\hline 20 & 421 & 48.61 & 161 & 96.87 & 264 & 163.31 & 134 & 21.86 & 4452 \\
\hline 40 & 421 & 48.54 & 161 & 96.10 & 264 & 163.03 & 135 & 21.47 & 2262 \\
\hline 60 & 421 & 46.30 & 161 & 95.93 & 264 & 164.26 & 135 & 19.80 & 1513 \\
\hline 120 & 421 & 47.34 & 161 & 97.64 & 265 & 164.25 & 135 & 19.44 & 763 \\
\hline
\end{tabular}


parameter from the null model was used to calculate AIC values in the algorithm step.gam, which tested all predictor variables for inclusion in the second model as cubic smoothing splines with 2 or 3 degrees of freedom. For the final model, the dispersion parameter from the second model was used to calculate the AIC values in the algorithm step.gam, which tested all predictor variables for inclusion as linear terms or cubic smoothing splines with 2 or 3 degrees of freedom.

A primary goal of our analyses was to explore the predictive power of models built at 6 different resolutions. Models built using an entire data set run the risk of being too complex (i.e. including too many variables or cubic smoothing splines with too many degrees of freedom) to enable accurate prediction of dolphin densities. Consequently, we used a 'pseudo-jackknife' cross validation approach to select our final model (Becker 2007). In particular, 4 data sets were constructed by excluding one of the $4 \mathrm{yr}$ of data. Cross validation data sets were created by excluding a year of data, rather than randomly selecting the excluded data, to explore the power of the models to predict dolphin densities in a novel year-a primary conservation and management application of the models. We also needed to ensure that the final model could adequately predict each individual year; consequently we added a 'pseudo-jackknife' component to the cross validation, as explained below, to minimize the influence of oceanographic conditions and species distribution patterns in any particular year on the selection of the final model (Becker 2007).

Dolphin encounter rate and group size models for each species were built for each resolution and data set; consequently, for each species there were 4 candidate encounter rate and 4 candidate group size models for each resolution. At each resolution, the candidate models (i.e. the selected variables and degrees of freedom for each cubic smoothing spline) were re-fit to the 3 remaining cross validation data sets, e.g. the candidate model built from the 1992, 1998, and 1999 data was re-fit to the 3 data sets: (1) 1992, 1998, and 2000; (2) 1992, 1999, and 2000; and (3) 1998, 1999, and 2000. Dolphin encounter rates and group sizes were predicted for each year omitted during model building and the average squared prediction error (ASPE) was calculated. Anscombe residuals (McCullagh \& Nelder 1989) were used in the ASPE calculations for the encounter rate models to account for the quasi-likelihood error distribution. A ratio estimator (Smith 1993) was used to correct the bias in group size predictions caused by reverse transforming the logarithm of group size predicted by the model (Finney 1941, Smith 1993). The sum of the ASPE values from each of the 4 fits of the 4 candidate models was used to select the best model for each species and resolution. Models having
ASPE sums within $5 \%$ of the lowest sum were considered to have equal predictive ability. In these cases, the best model was defined as the candidate model that had the lowest ASPE value when predicting the year that was excluded from model building. The best model was then re-fit using all 4 years of data to produce the final models at each resolution. The predictive power of the final models was evaluated using ratios of observed to predicted dolphin relative abundance (defined as the number of encounters multiplied by the average group size). Specifically, the observed and predicted number of dolphins were calculated for each segment and summed for all segments within a year or for all years.

Predicted dolphin densities, $D$, were obtained for each segment using a line-transect formula:

$$
D=\frac{\text { Sightings } \times \exp (\text { LGS }) \times \text { Ratio } \times f(0)}{2 \times \text { Distance } \times g(0)}
$$

where Sightings is the predicted number of sightings, LGS is the predicted logarithm of group size, Ratio is the ratio estimator used to correct for potential bias created by modeling logarithmic school sizes, Distance is distance in kilometers traveled on effort in the segment, and $f(0)$ and $g(0)$ are line-transect variables that respectively correct for a decrease in detection probability with distance from the transect and detection probabilities on the transect that are $<1$ (Buckland et al. 2001). Values of $f(0)$ and $g(0)$ for predicted group sizes in each segment were obtained from Ferguson \& Barlow (2001); specifically, we used their estimates of $f(0)$ from the ETP region. The group-size independent $f(0)$ values reported for the 3 stocks of common dolphin were averaged.

We calculated the correlation between predicted densities at the different resolutions by assigning the predictions for the larger segments to all of the smaller segments they contained. There was a mismatch between the 40 and $60 \mathrm{~km}$ segments for each day; consequently, the prediction for the $40 \mathrm{~km}$ segment that overlapped both $60 \mathrm{~km}$ segments was arbitrarily assigned to the prediction for the first $60 \mathrm{~km}$ segment. We created a $95 \%$ confidence interval (CI) for the average of the correlation values by randomly permuting the predicted densities in the smaller segments for the entire survey data set and recalculating the correlation 1000 times; the CI was determined by the 25th and 975th ordered values of the permutation. If the observed correlation was not contained in the $95 \%$ CI, it was assumed to be statistically significant from the correlation that would be obtained from a random distribution. We mapped predicted densities at all resolutions by assigning the predicted density to the midpoint of each segment and interpolating these points in a $10 \times 10 \mathrm{~km}$ grid using negative exponential distance weighting (circular neighborhood of $300 \mathrm{~km}$, weights reached 0.5 at $100 \mathrm{~km}$ ). 


\section{RESULTS}

Dispersion parameters for the final encounter rate models ranged from 2.36 to 0.87 ; this range is appreciably different from 1, the value expected for a Poisson distribution, and justifies the use of the quasilikelihood error distribution. The models with the lowest ASPE in our cross validation analysis were generally built using the same data subset for a majority of spatial resolutions for each species, but the data subsets tended to differ between encounter rate and group size models for each species and among species (Table 2). Typically, the best model was the candidate model that had the lowest ASPE value when predicting the year that was omitted from model building because the ASPE sums for multiple models were within $5 \%$ of one another. In general, there was no pattern in the number of variables selected at the different resolutions. The variables included in the final encounter rate and group size models for a particular species, however, were not a random collection. The same variables frequently appeared at multiple resolutions and had similarly shaped cubic smoothing splines.

Final encounter rate and group size models are shown for all species at the $40 \mathrm{~km}$ resolution in Fig. 4. The patterns shown in this figure are generally indicative of the patterns observed at all scales. In general, models for all species suggest that encounter rates are influenced by temperature and the properties of the thermocline (Fig. 4). The encounter rate models for all species at all resolutions include Beaufort sea state, as expected due to the increased difficulty of detecting groups in higher Beaufort sea states. The percentage of explained deviance for the encounter rate models at the $40 \mathrm{~km}$ resolution ranged from 18 (striped dolphin) to 30 (eastern spinner dolphin), and from 7 (eastern spinner dolphin) to 26 (Risso's dolphin) for the group size models (Table 3). The percentage of explained deviance generally increases with increasing spatial

Table 2. Final encounter rate and group size models had the lowest average squared prediction error in the cross validation analyses (see 'Materials and methods - Data analyses' for details). The years excluded from the cross validation data sets for the final models are shown for each species and spatial resolution. Predictor variables selected in the final models are also shown; the order of variables corresponds to the consistency with which the variables were selected among resolutions. Fronts: differences between the minimum and maximum temperatures on a segment; Temp: sea surface temperature; Sal: sea surface salinity; TCD: thermocline depth; TCS: thermocline strength; Chl: natural logarithm of surface chlorophyll concentrations. Species taxa are given in Table 1

\begin{tabular}{|c|c|c|c|c|}
\hline \multirow{2}{*}{$\begin{array}{l}\text { Spatial } \\
\text { resolution }(\mathrm{km})\end{array}$} & Encounter rate & \multicolumn{3}{|c|}{ Group size } \\
\hline & Excluded year & Predictor variables & Excluded year & Predictor variables \\
\hline \multicolumn{5}{|l|}{ Striped dolphin } \\
\hline 2 & 1998 & Depth TCD TCS Beaufort & 2000 & TCD TCS \\
\hline 10 & 1998 & Depth TCD TCS Beaufort & 2000 & TCD TCS \\
\hline 20 & 1998 & Beaufort Temp & 2000 & TCD TCS Fronts \\
\hline 40 & 1998 & Depth TCD TCS Beaufort & 2000 & TCS Fronts Temp Sal \\
\hline 60 & 1998 & Depth TCD TCS Beaufort & 2000 & TCD TCS \\
\hline 120 & 1998 & Depth TCD TCS Beaufort & 1999 & TCD TCS \\
\hline \multicolumn{5}{|c|}{ Eastern spinner dolphin } \\
\hline 2 & 1999 & Depth Temp TCD Beaufort TCS & 1999 & Temp \\
\hline 10 & 1999 & Depth Temp TCD Beaufort & 1999 & Temp \\
\hline 20 & 1999 & Depth Temp TCD Beaufort & 1999 & Temp \\
\hline 40 & 2000 & Depth Temp TCD Beaufort & 1992 & Temp \\
\hline 60 & 1998 & Depth Temp TCD Beaufort Chl & 1999 & Temp \\
\hline 120 & 2000 & Depth Temp TCD Beaufort TCS & 1992 & Temp Fronts \\
\hline \multicolumn{5}{|c|}{ Short-beaked common dolphin } \\
\hline 2 & 1998 & Temp TCD Beaufort Depth Chl & 1992 & Sal Chl Beaufort Depth Fronts \\
\hline 10 & 1998 & Temp TCD Beaufort Depth & 1992 & Sal Chl Beaufort \\
\hline 20 & 1998 & Temp TCD Beaufort Depth Chl & 1998 & Sal Chl Beaufort \\
\hline 40 & 1998 & Temp TCD Beaufort Depth Chl Fronts TCS & 1992 & Chl Beaufort \\
\hline 60 & 2000 & Temp TCD Beaufort Depth Chl & 1992 & Beaufort Depth \\
\hline 120 & 1999 & Temp TCD Beaufort & 1992 & Sal Chl Beaufort \\
\hline \multicolumn{5}{|l|}{ Risso's dolphin } \\
\hline 2 & 1998 & Depth Beaufort Chl & 1992 & Beaufort \\
\hline 10 & 2000 & Depth Beaufort Chl Temp TCD & 1998 & Beaufort \\
\hline 20 & 2000 & Depth Beaufort Chl Temp TCD & 1998 & Beaufort Depth \\
\hline 40 & 2000 & Depth Beaufort Chl Temp TCD & 1992 & Beaufort Depth \\
\hline 60 & 1998 & Depth Beaufort & 1992 & Beaufort Depth \\
\hline 120 & 2000 & Depth Beaufort & 1999 & Beaufort Depth \\
\hline
\end{tabular}


A Encounter rate Striped dolphin
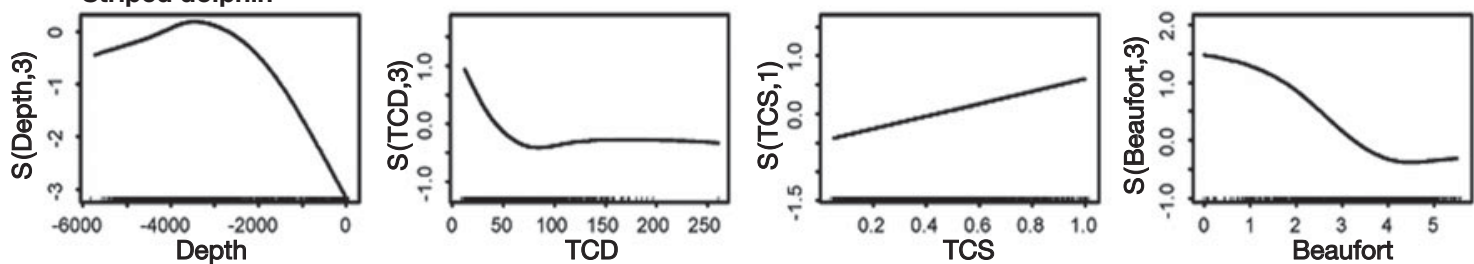

Eastern spinner dolphin
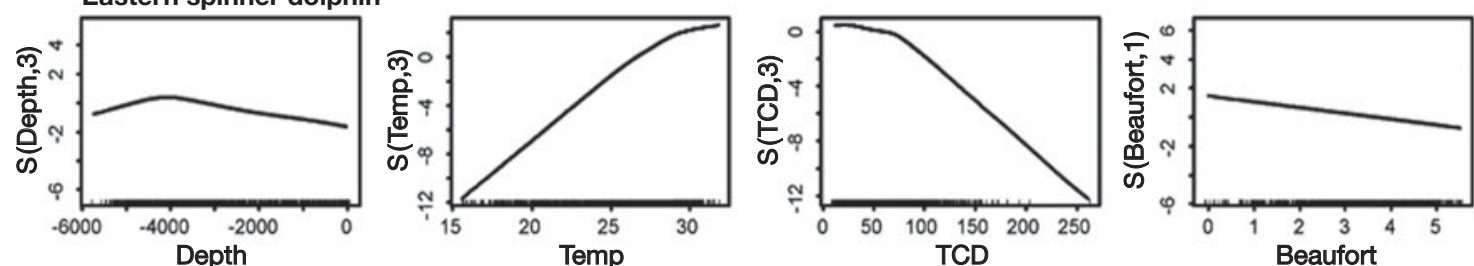

Short-beaked common dolphin
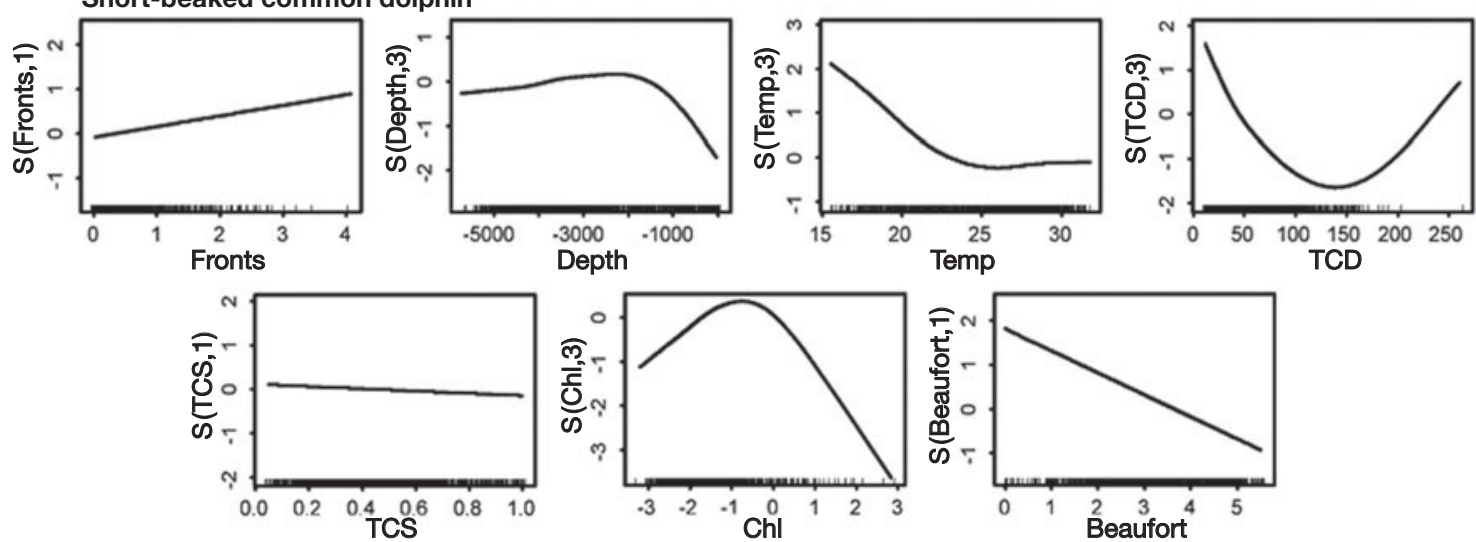

Risso's dolphin
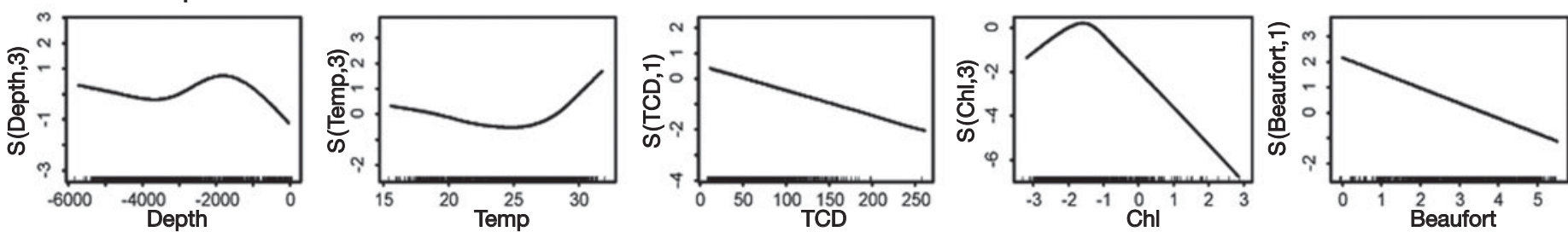

Fig. 4. (A) Final encounter rate and (B) group size models for all dolphin species at the $40 \mathrm{~km}$ resolution. Fronts: differences between the minimum and maximum temperatures on a segment; Temp: sea surface temperature; Sal: sea surface salinity; TCD: thermocline depth; TCS: thermocline strength; Chl: natural logarithm of surface chlorophyll concentrations. The $y$-axes, representing the smoothing spline function and labeled to indicate the degrees of freedom for the spline (linear terms are represented by a single degree of freedom), have been scaled across all resolutions relative to the variable having the largest $y$-axis range that was not influenced by a small number of outlying points; the scale of the $y$-axes was determined separately for the encounter rate and group size models for each species. Data points for each variable are indicated by tick marks along the $x$-axis. Species taxa are given in Table 1

resolution for the encounter rate models, which is likely an outcome of the larger sample size that includes a larger proportion of zeroes at the smaller resolutions. This pattern is less pronounced for the group size models, where sample size is relatively consistent because only segments containing a sighting are used to build the models.

The product-moment correlation coefficients between densities predicted at the different resolutions were quite high (Table 4), with average values ranging from 0.77 (Risso's dolphin) to 0.92 (striped dolphin). These correlations were considered significant because the confidence interval for the average correlation from a random distribution ranged from -0.01 to 0.01 . Hence, the models built at all resolutions identified the same areas of high and low densities for each species. The $40 \mathrm{~km}$ model results suggest a mean density of 94 ind. per $1000 \mathrm{~km}^{2}$ for striped dolphin (range: 


\section{B Group size} Striped dolphin
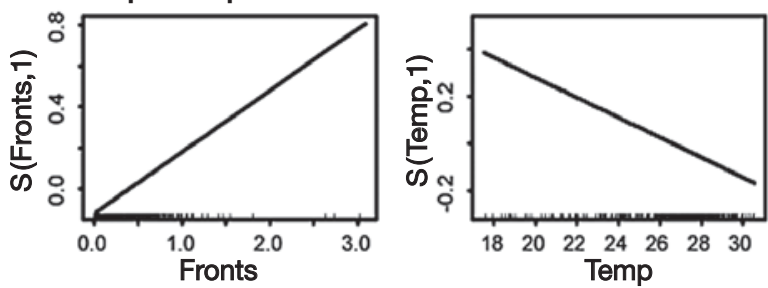

Eastern spinner dolphin

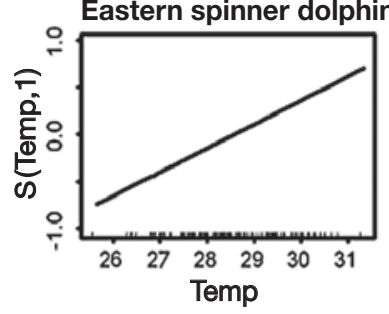

Short-beaked common dolphin
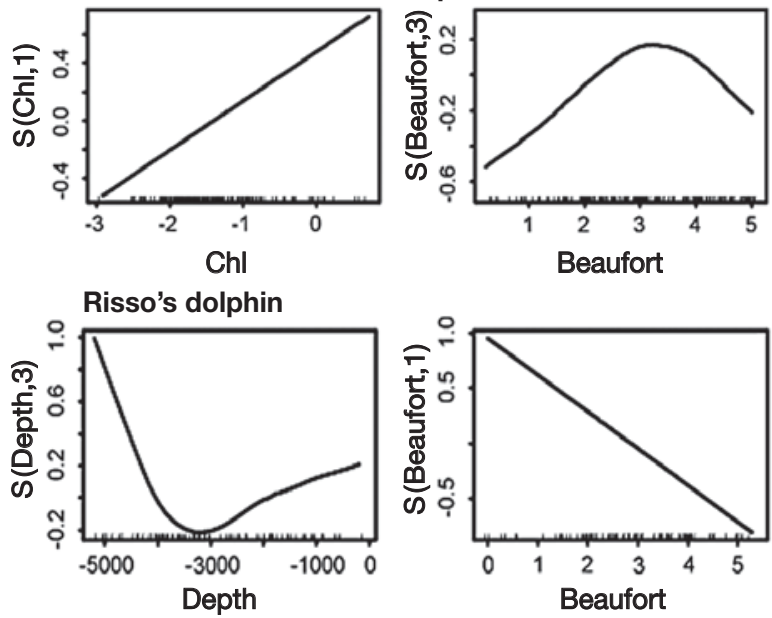

Fig. 4 (continued)
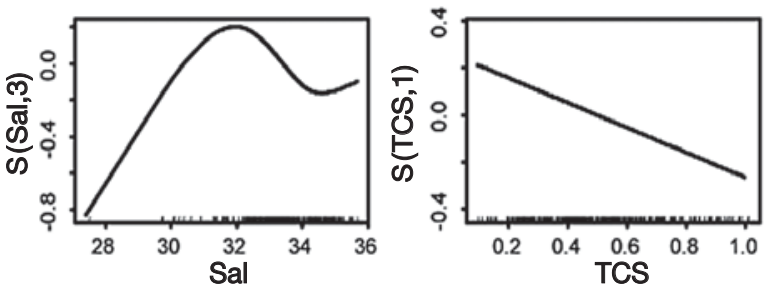

\section{DISCUSSION}

\section{Dolphin-habitat relationships in the ETP}

For each species, models built at different resolutions showed similar ecological patterns. For example, species densities predicted by encounter rate and group size models built at 2 to $120 \mathrm{~km}$ resolutions are

Table 3. Percentage of deviance explained by the final encounter rate and group size models at the $40 \mathrm{~km}$ resolution is shown for each species. For all species, encounter rate models built at the larger spatial resolutions explain a greater percentage of the deviance than models built at the smaller resolutions. The pattern is not as pronounced for the group size models and does not hold for all species (see 'Results' for details). Species taxa are given in Table 1

\begin{tabular}{|lcc|}
\hline & $\begin{array}{c}\text { Encounter } \\
\text { Rate }\end{array}$ & $\begin{array}{c}\text { Group } \\
\text { Size }\end{array}$ \\
\hline Striped dolphin & 18.3 & 7.6 \\
Eastern spinner dolphin & 30.3 & 7.0 \\
Short-beaked common dolphin & 28.7 & 9.9 \\
Risso's dolphin & 23.4 & 26.0 \\
\hline
\end{tabular}

Table 4. Averages of the product-moment correlation coefficients between densities predicted for each resolution (e.g. the average of the correlation coefficients between 2 and 10, 2 and 20,2 and 40, 2 and 60, and 2 and 120 is shown for the $2 \mathrm{~km}$ resolution) and all resolutions are shown. The correlation values are high, suggesting that all models identify similar areas of high and low dolphin densities. Species taxa are given in Table 1

\begin{tabular}{|lcccc|}
\hline $\begin{array}{l}\text { Spatial } \\
\text { resolution } \\
(\mathrm{km})\end{array}$ & $\begin{array}{c}\text { Striped } \\
\text { dolphin }\end{array}$ & $\begin{array}{c}\text { Eastern } \\
\text { spinner } \\
\text { dolphin }\end{array}$ & $\begin{array}{c}\text { Short-beaked } \\
\text { common } \\
\text { dolphin }\end{array}$ & $\begin{array}{c}\text { Risso's } \\
\text { dolphin }\end{array}$ \\
\hline 2 & 0.93 & 0.92 & 0.85 & 0.75 \\
10 & 0.93 & 0.93 & 0.80 & 0.81 \\
20 & 0.92 & 0.93 & 0.84 & 0.83 \\
40 & 0.92 & 0.92 & 0.79 & 0.74 \\
60 & 0.92 & 0.91 & 0.79 & 0.75 \\
120 & 0.89 & 0.81 & 0.66 & 0.72 \\
All & 0.92 & 0.90 & 0.79 & 0.77 \\
\hline
\end{tabular}


Table 5. Ratios of observed to predicted dolphin relative abundance are shown for all species and resolutions. Predicted relative abundance was obtained by multiplying results from the final encounter rate and group size models; ratios were calculated by summing the relative abundance for all segments within a year or for all years. The standard error of the ratios (SE) was calculated using the values from the individual years. Species taxa are given in Table 1

\begin{tabular}{|c|c|c|c|c|c|c|}
\hline & \multirow[b]{2}{*}{$2 \mathrm{~km}$} & & \multicolumn{2}{|c|}{ Spatial resolution } & \multirow[b]{2}{*}{$60 \mathrm{~km}$} & \multirow[b]{2}{*}{$120 \mathrm{~km}$} \\
\hline & & $10 \mathrm{~km}$ & $20 \mathrm{~km}$ & $40 \mathrm{~km}$ & & \\
\hline \multicolumn{7}{|c|}{ Striped dolphin } \\
\hline 1992 & 1.611 & 1.602 & 1.430 & 1.594 & 1.586 & 1.572 \\
\hline 1998 & 0.923 & 0.920 & 0.904 & 0.977 & 1.012 & 1.000 \\
\hline 1999 & 0.785 & 0.784 & 0.770 & 0.766 & 0.794 & 0.796 \\
\hline 2000 & 0.933 & 0.929 & 0.976 & 0.916 & 1.000 & 0.987 \\
\hline All years & 1.001 & 0.998 & 0.979 & 1.005 & 1.047 & 1.039 \\
\hline $\mathrm{SE}$ & 0.186 & 0.184 & 0.143 & 0.182 & 0.170 & 0.168 \\
\hline \multicolumn{7}{|c|}{ Eastern spinner dolphin } \\
\hline 1992 & 0.653 & 0.633 & 0.634 & 0.620 & 0.635 & 0.744 \\
\hline 1998 & 1.154 & 1.144 & 1.143 & 1.187 & 1.199 & 1.108 \\
\hline 1999 & 0.896 & 0.850 & 0.846 & 0.872 & 0.807 & 0.680 \\
\hline 2000 & 0.977 & 1.038 & 1.043 & 1.025 & 1.042 & 1.003 \\
\hline All years & 0.992 & 0.987 & 0.987 & 1.002 & 0.997 & 0.938 \\
\hline $\mathrm{SE}$ & 0.104 & 0.112 & 0.113 & 0.121 & 0.125 & 0.102 \\
\hline \multicolumn{7}{|c|}{ Short-beaked common dolphin } \\
\hline 1992 & 1.611 & 1.686 & 1.532 & 1.395 & 1.627 & 1.802 \\
\hline 1998 & 0.722 & 0.686 & 0.756 & 0.766 & 0.722 & 0.657 \\
\hline 1999 & 0.949 & 0.961 & 0.917 & 0.938 & 0.910 & 0.955 \\
\hline 2000 & 1.074 & 1.027 & 1.053 & 1.058 & 1.029 & 0.871 \\
\hline All years & 0.988 & 0.971 & 0.980 & 0.979 & 0.967 & 0.926 \\
\hline $\mathrm{SE}$ & 0.189 & 0.212 & 0.167 & 0.133 & 0.196 & 0.251 \\
\hline \multicolumn{7}{|c|}{ Risso's dolphin } \\
\hline 1992 & 0.429 & 0.454 & 0.408 & 0.437 & 0.464 & 0.453 \\
\hline 1998 & 1.223 & 1.059 & 1.053 & 1.060 & 1.354 & 1.174 \\
\hline 1999 & 0.996 & 0.954 & 0.966 & 1.032 & 1.040 & 1.057 \\
\hline 2000 & 0.900 & 1.077 & 1.002 & 0.951 & 0.907 & 1.010 \\
\hline All years & 0.975 & 0.962 & 0.934 & 0.947 & 1.034 & 1.011 \\
\hline $\mathrm{SE}$ & 0.167 & 0.146 & 0.151 & 0.146 & 0.185 & 0.161 \\
\hline
\end{tabular}

Reilly (1990) and Reilly \& Fiedler (1994) obtained weak relationships between striped dolphin distributions and oceanographic variables. Striped dolphin encounter rate models had the lowest explained deviance among the 4 species in our study (Table 3), supporting the hypothesis that the broad distribution of striped dolphin (Fig. 5) made it difficult for the models to capture dominant habitat patterns using oceanographic variables. The variables selected in our models suggest that striped dolphin encounters decrease in depths less than $3000 \mathrm{~m}$ and increase when the thermocline is strong and shallow (Fig. 4). Upwelling modified waters are defined by cooler temperatures, weak and shallow thermoclines, and high surface chlorophyll concentrations in the ETP, while tropical waters are defined by warmer temperatures, strong and deep thermoclines, and lower surface chlorophyll concentrations. Hence, encounter rate models for striped dolphin relate to elements of both habitat types, similar to the findings of Reilly (1990) and Reilly \& Fiedler (1994). Striped dolphin group sizes tended to be larger when the thermocline was shallow and weak, which is consistent with upwelling modified waters, although the association between larger groups and shallow thermoclines was replaced by an association with cooler, more saline highly correlated (Table 4). Additionally, key variables (identified by large changes in the mean response over the range of the variable) were included in encounter rate and group size models built at a majority of resolutions and had similar functional forms for each species.

Our exploration of the effect of spatial resolution on dolphin-habitat models builds on 3 decades of dolphin-habitat studies in the ETP (Au \& Perryman 1985, Reilly 1990, Reilly \& Fiedler 1994, Reilly et al. 2002). Our analyses used 3 of the same years of data as Reilly et al. (2002), but the technique used to assess species-habitat relationships differs as does our treatment of resolution. In particular, Reilly et al. (2002) used an ordination technique to analyze data collected in the ETP from 1986 to 1990 and 1998 to 2000, and selected a survey day as the unit of analysis; a survey day translates to a $\sim 160 \mathrm{~km}$ resolution (Reilly et al. 2002); although Reilly \& Fiedler (1994), who also used a survey day as the unit of analysis for data collected in the ETP from 1986 to 1990, found that the distance traveled can vary substantially (i.e. 37 to $222 \mathrm{~km}$ ). waters at the $40 \mathrm{~km}$ resolution (Fig. 4). While temperature only entered the group size models built at the $40 \mathrm{~km}$ resolution, the association between large groups and waters with higher salinities was observed at the 40 to $120 \mathrm{~km}$ resolutions.

All previous studies of dolphin habitat in the ETP (Au \& Perryman 1985, Reilly 1990, Reilly \& Fiedler 1994, Reilly et al. 2002) found spinner dolphin in tropical waters and common dolphin in upwelling modified waters. Densities of eastern spinner dolphin predicted by our models are highest along the coasts of Mexico, Guatemala, and El Salvador (Fig. 5), similar to the results of previous studies. Encounter rates and group sizes for eastern spinner dolphin increase in warm temperatures, which identifies tropical waters. Within these waters, however, higher encounters occur when the thermocline is shallow, which contrasts with previous results (Reilly \& Fiedler 1994).

Maps of predicted densities for common dolphin suggest that the equatorial cold tongue, Costa Rica Dome, and areas off the coast of Baja California are important habitat (Fig. 5). Encounter rate models for 


\section{Striped dolphin}

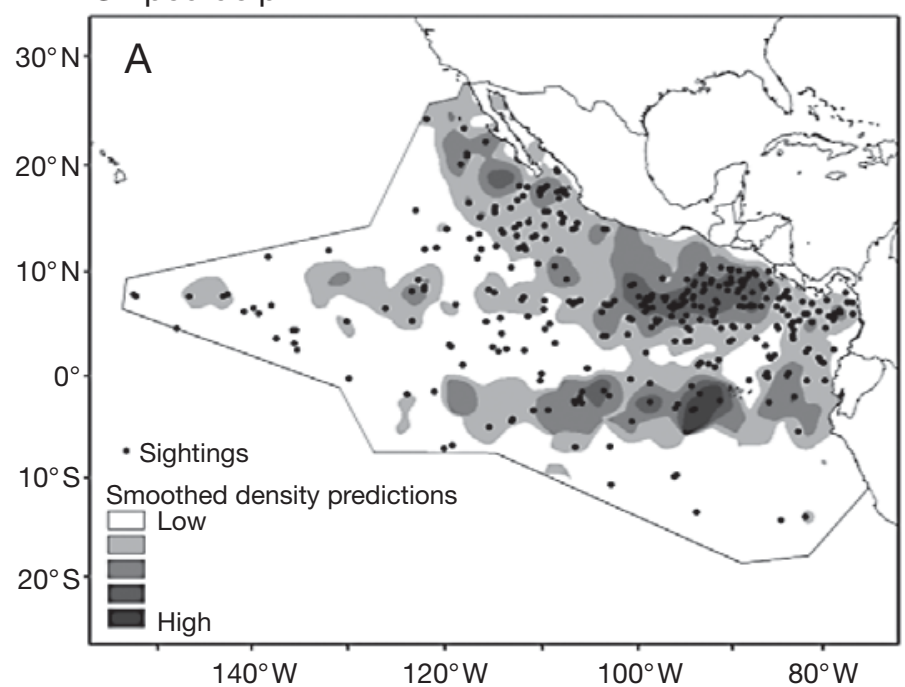

Short-beaked common dolphin

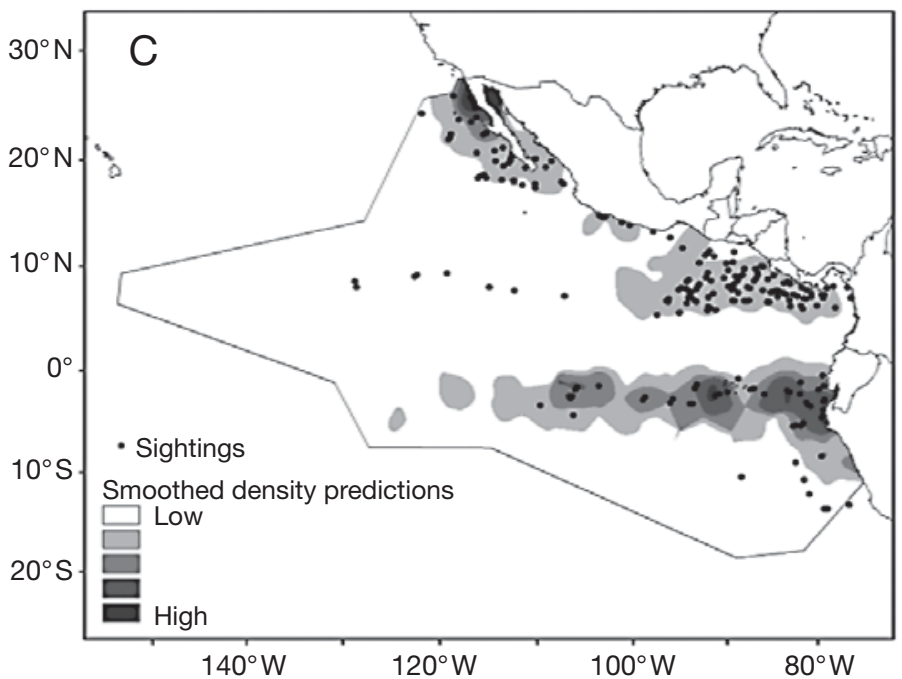

\section{Eastern spinner dolphin}

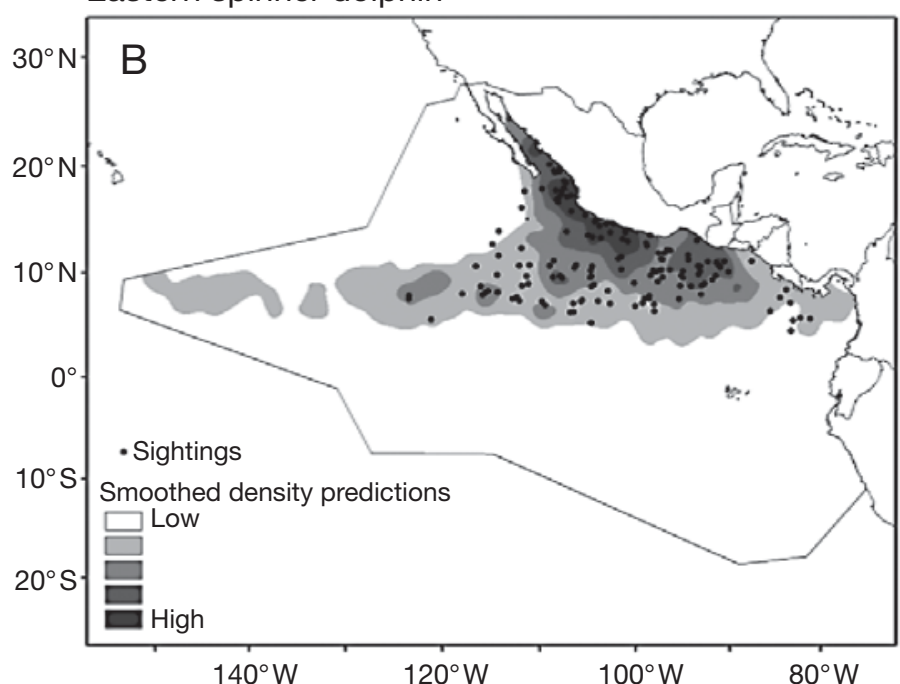

Risso's dolphin

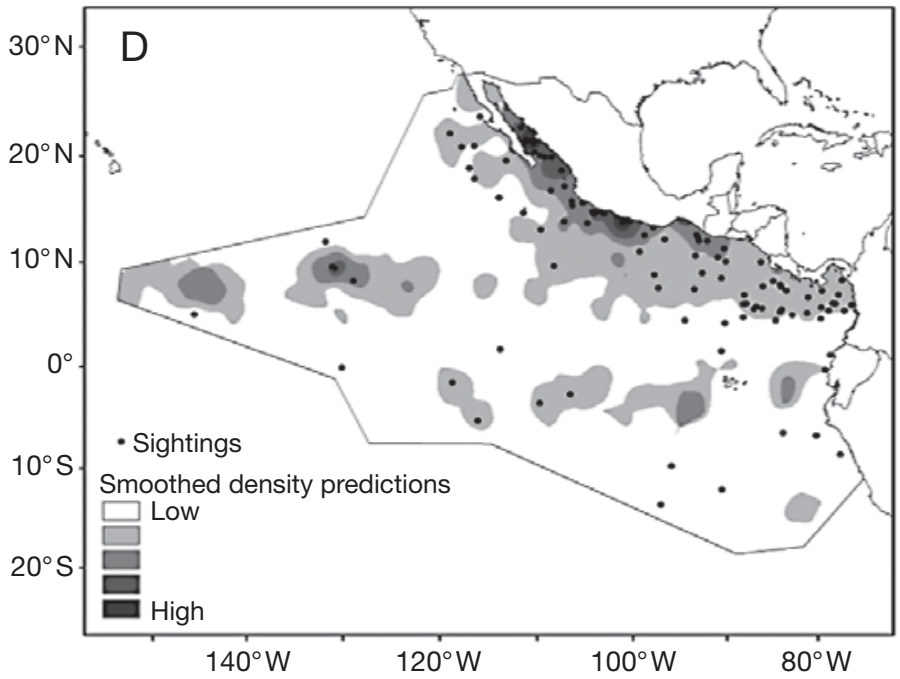

Fig. 5. Densities were predicted using the final encounter rate and group size models built at the $40 \mathrm{~km}$ resolution and interpolated in a $10 \times 10 \mathrm{~km}$ grid using negative exponential distance weighting (see 'Materials and methods' for details) for (A) striped dolphin Stenella coeruleoalba, (B) eastern spinner dolphin S. longirostris orientalis, (C) short-beaked common dolphin Delphinus delphis, and (D) Risso's dolphin Grampus griseus. Densities scale from the lowest values shown in white to the highest values shown in dark grey; sightings of each species are shown as black dots. Density values within each shade category differ among species

common dolphin mirror this pattern with increased encounters occurring in cooler temperatures and shallow thermoclines (the increase in common dolphin encounters for thermocline depths greater than $150 \mathrm{~m}$ appears to be driven by a few outliers, Fig. 4). Encounters peak in intermediate chlorophyll concentrations (Fig. 4), however, which is unexpected for upwelling modified waters. Common dolphin groups tended to be largest in waters with high salinity and chlorophyll concentrations, although the association between large groups and high salinity was not found at the $40 \mathrm{~km}$ resolution (Fig. 4) and the association between large groups and high chlorophyll concentrations was replaced by an association with shallow waters at the $60 \mathrm{~km}$ resolution.

Habitat for Risso's dolphin was only explored in the qualitative analyses of Au \& Perryman (1985). They suggested that Risso's dolphin occurred in both upwelling modified and tropical waters. The high-density areas predicted by our models for Risso's dolphin overlap with high-density areas for common and eastern spinner dolphin (Fig. 5), supporting their finding. Encounters of Risso's dolphin also reflect properties of both upwelling modified and tropical waters: encounters generally increase when the temperature is warm and the thermocline is shallow and decrease in waters with higher 
chlorophyll concentrations (Fig. 4). Group sizes were not generally related to any oceanographic variables, but only showed an increase with depth (Fig. 4).

The general correspondence between the models we built at all resolutions and previously documented dolphin-habitat relationships, as well as the general similarity among the models built at all resolutions, suggest that resolution, within a range of 2 to $120 \mathrm{~km}$, does not affect the identification of ecological patterns in ETP dolphin-habitat models. No direct comparisons of the percentage of explained deviance were available for the species we modeled. However, Reilly et al. (2002) found that their canonical correspondence analyses of daily encounter rates using similar oceanographic variables explained $16 \%$ of the variance for striped dolphin, $8 \%$ for eastern spinner dolphin, and $50 \%$ for common dolphin. Our percentages of explained deviance at the $120 \mathrm{~km}$ resolution were higher for striped $(27 \%)$ and eastern spinner dolphin $(43 \%)$, but lower for short-beaked common dolphin (30\%). Ferguson et al. (2006a) used GAMs and a $~ 9 \mathrm{~km}$ spatial resolution to relate delphinid encounter rates and group sizes to many of the oceanographic variables considered in our analyses. The percentage of explained deviance in the delphinid encounter rate models $(12 \%$, Ferguson et al. 2006a) was intermediate between the percentage of explained deviance for our striped and eastern spinner dolphin models built at the $10 \mathrm{~km}$ resolution (11 and 19\%, respectively) and lower than the values for the striped and eastern spinner dolphin models built at the $40 \mathrm{~km}$ resolution (18 and $30 \%$, respectively). The percentage of explained deviance in the delphinid group size models $(5 \%$, Ferguson et al. 2006a) was at the lower end of the percentage of explained deviance for our striped and Risso's dolphin models built at all resolutions (6 and 26\%, respectively). In our analyses and Ferguson et al. (2006a), encounter rate models generally had a higher percentage of explained deviance than group size models. This result may suggest that the oceanographic variables used in these studies are not effective proxies for the complex factors influencing dolphin group sizes, such as behavior, ability to capture prey, and protection from predators. This hypothesis is supported by the analyses of Reilly \& Fiedler (1994); they found that groups of all sizes occurred in the same habitats and that group size was not strongly related to oceanographic variables within a habitat.

\section{Predictive power: the importance of interannual habitat variability}

The importance of interannual variability is clearly shown in our yearly ratios of observed to predicted dol- phin relative abundance. For all species considered in our analyses, the predictive power of the GAMs varied more among years than among spatial resolutions (Table 5). For the spatial resolutions analyzed in our study, these results suggest that interannual habitat variability has a greater impact on the predictive power of dolphin-habitat models than the resolution of the unit of analysis. ENSO produces strong interannual variability in the ETP with a period of 2 to $7 \mathrm{yr}$ (Fiedler 2002a). A number of oceanographic changes associated with ENSO are expected to affect prey densities and concomitantly the density of apex marine predators. Although the relationships among interannual variability in oceanographic conditions, mid-trophic species, and apex predators are not fully understood, the patterns of interannual variability in the predictive power of our models suggests that ENSO may influence dolphin distributions and, hence, their densities within our study area.

\section{Domains of scale in the ETP: selecting the best resolution}

Although it is common to find scale dependence in species-habitat relationships for a variety of organisms in a wide range of ecosystems, domains of scale exist in which ecological patterns do not change, or change monotonically, with scale (Wiens 1989). Within a domain, patterns may be extrapolated across scales; extrapolation across domains is not possible because observed species-habitat relationships may differ among domains (Wiens 1989). The absence of scale dependence in our models suggests that resolutions from 2 to $120 \mathrm{~km}$ occur within a single domain of scale in the ETP.

Previous studies have found scale dependence in seabird-habitat relationships. Although differences between seabirds and dolphins, such as size, diving abilities, and energetic constraints, may contribute to the absence of scale dependence observed in our study, the absence may also be the result of differences in our study design and area. For example, we defined habitat using oceanographic variables that are expected to be proxies for prey abundance, while seabird studies frequently define habitat using direct measures of prey abundance. While it would be difficult to collect detailed prey data for a large pelagic region such as the ETP, it is possible that scale dependence among the resolutions considered here would occur in models relating dolphins to habitat variables that are trophically closer to prey species. Additionally, it is possible that resolutions larger than $120 \mathrm{~km}$ may occur outside of the domain of scale we observed in the ETP. Consequently, analyses conducted at larger resolutions may exhibit scale dependence. 
The absence of scale dependence in our models may also be ecosystem dependent. Most scale dependent seabird-habitat relationships have been observed in temperate or high latitude ecosystems, particularly in waters on the continental shelf or around islands, where habitat is expected to change on smaller spatial scales. We examined dolphin-habitat relationships in the ETP biogeographic province, where much of the physical oceanography is defined by large-scale processes, including current systems and variability in rates of evaporation and precipitation (Fiedler \& Talley 2006). It is possible that the approximately $55 \mathrm{~km} \mathrm{sam-}$ pling scale of the water column and surface chlorophyll data fails to capture fine-scale variability and that models built using more frequently sampled oceanographic data would be scale dependent. However, we conducted analyses using only the oceanographic and geographic data that were collected at all resolutions (i.e. sea surface temperature and salinity, temperature fronts, and depth) and found similar results to those presented here. Hence, the similarity of the models at all resolutions may indicate that the dominant oceanographic variability is captured by the sampling scale or that cetaceans are not responding to fine-scale oceanographic variability in the ETP. Additional analyses are needed to examine these hypotheses. For example, oceanographic variability is expected to occur on finer scales in the northeastern Pacific, particularly in the California Current Ecosystem. It is possible that dolphin-habitat models built at resolutions from 2 to $120 \mathrm{~km}$ may show scale dependence in such regions.

Habitat models are potentially powerful tools for incorporating heterogeneity in marine ecosystems into the management and conservation of dolphins, many of which are substantially impacted by human activities. In the ETP, dolphin management and conservation focuses heavily on interactions between species and a variety of fisheries. Combining model predictions of dolphin density with estimates of fishing intensity can help identify areas of potentially frequent interactions that may result in dolphin bycatch or other adverse population effects. To date, quantitative dolphin-habitat models have been developed for only a small proportion of the species impacted by anthropogenic activities in the ETP.

Our dolphin-habitat models suggest that resolutions from 2 to $120 \mathrm{~km}$ occur within a single domain of scale in the ETP. In particular, similar results are achieved by models built using oceanographic habitat variables at any of these resolutions for species that are broadly distributed in the ETP. A plausible hypothesis is that the domain of scale is defined by the relative homogeneity of the oceanographic variables throughout these resolutions. This hypothesis suggests that the consequence of changing resolutions is a change in the signal-to-noise ratio. Specifically, the number of segments containing a zero is drastically reduced at the larger resolutions for all species (see Table 1 for a general indication, although note that some segments may contain more than 1 encounter). The similarity of results from all models suggests that the large number of segments containing a zero at the smaller resolutions do not contain ecological information about the dolphin-habitat relationships. Consequently, it may be appropriate to develop predictive dolphin-habitat models for species that are broadly distributed in the ETP at larger resolutions when habitat is defined using oceanographic variables. There is a trade-off, however, between using larger resolutions and maximizing sample size. The total ETP data set contains $909 \mathrm{~d}$ of survey effort. We had to restrict our analyses to days in which the ship traveled $120 \mathrm{~km}$ (a total of $817 \mathrm{~d}$ ) and days in which complete oceanographic data was collected $(763 \mathrm{~d})$; we also had to exclude effort that occurred outside the $120 \mathrm{~km}$ segment. Using intermediate resolutions, such as the $40 \mathrm{~km}$ resolution presented here, may provide an optimal solution to this trade-off because it minimizes false absences and allows the inclusion of more survey days and more effort per day.

Acknowledgements. This study would not have been possible without the tireless field efforts of the crew and scientists aboard the 'David Starr Jordan', the 'McArthur', and the 'Endeavor'. We also thank C. Redfern, R. Cosgrove, M. Ferguson, P. Fiedler, K. Forney, N. Friday, R. Pitman, S. Reilly, and 2 anonymous reviewers for insightful comments on our analyses and manuscript. Funding from the U.S. Strategic Environmental Research and Development Program supported this research; additional support for J.V.R was provided by the National Research Council Postdoctoral Associateship program.

\section{LITERATURE CITED}

Au DWK, Perryman WL (1985) Dolphin habitats in the Eastern Tropical Pacific. Fish Bull (Wash DC) 83:623-643

Ballance LT, Pitman RL, Fiedler PC (2006) Oceanographic influences on seabirds and cetaceans of the eastern tropical Pacific: a review. Prog Oceanogr 69:360-390

Barlow J, Gerrodette T, Forcada J (2001) Factors affecting perpendicular sighting distances on shipboard linetransect surveys for cetaceans. J Cetacean Res Manag 3: 201-212

Becker EA (2007) Predicting seasonal patterns of California cetacean density based on remotely sensed environmental data. PhD dissertation, University of California, Santa Barbara, CA

Buckland ST, Anderson DR, Burnham KP, Laake JL, Borchers DL, Thomas L (2001) Introduction to distance sampling: estimating abundance of biological populations. Oxford University Press, Oxford

Cairns DK, Schneider DC (1990) Hot spots in cold water: feeding habitat selection by thick-billed murres. Stud Avian Biol 14:52-60 
Chambers JM, Hastie TJ (1991) Statistical models in S. Chapman \& Hall/CRC, Boca Raton, FL

$>$ Davoren GK, Montevecchi WA, Anderson JT (2002) Scaledependent associations of predators and prey: constraints imposed by flightlessness of common murres. Mar Ecol Prog Ser 245:259-272

Erikstad KE, Moum T, Vader W (1990) Correlations between pelagic distribution of common and Brünnich's guillemots and their prey in the Barents Sea. Polar Res 8:77-87

Fauchald P (1999) Foraging in a hierarchical patch system. Am Nat 153:603-613

Fauchald P, Erikstad KE, Skarsfjord H (2000) Scale-dependent predator-prey interactions: the hierarchical spatial distribution of seabirds and prey. Ecology 81:773-783

Ferguson MC, Barlow J (2001) Spatial distribution and density of cetaceans in the eastern tropical Pacific Ocean based on summer/fall research vessel surveys in 1986-96. Report No. LJ-01-04, Southwest Fisheries Science Center, La Jolla, CA

Ferguson MC, Barlow J, Fiedler P, Reilly SB, Gerrodette T (2006a) Spatial models of delphinid (family Delphinidae) encounter rate and group size in the eastern tropical Pacific Ocean. Ecol Modell 193:645-662

Ferguson MC, Barlow J, Reilly SB, Gerrodette T (2006b) Predicting Cuvier's (Ziphius cavirostris) and Mesoplodon beaked whale population density from habitat characteristics in the eastern tropical Pacific Ocean. J Cetacean Res Manag 7:287-299

Fiedler PC (2002a) Environmental change in the eastern tropical Pacific Ocean: review of ENSO and decadal variability. Mar Ecol Prog Ser 244:265-283

> Fiedler PC (2002b) The annual cycle and biological effects of the Costa Rica Dome. Deep-Sea Res I 49:321-338

Fiedler PC, Philbrick VA (2002) Environmental change in the eastern tropical Pacific Ocean: observations in 1986-1990 and 1998-2000. Report No. LJ-02-15, NOAA, National Marine Fisheries Service, Southwest Fisheries Science Center, La Jolla, CA

> Fiedler PC, Talley LD (2006) Hydography of the eastern tropical Pacific: a review. Prog Oceanogr 69:143-180

Finney DJ (1941) On the distribution of a variate whose logarithm is normally distributed. J R Stat Soc [Ser A] (Suppl 7):155-161

Forney KA (2000) Environmental models of cetacean abundance: reducing uncertainty in population trends. Conserv Biol 14:1271-1286

Gerrodette T, Forcada J (2005) Non-recovery of two spotted and spinner dolphin populations in the eastern tropical Pacific Ocean. Mar Ecol Prog Ser 291:1-21

Hamazaki T (2002) Spatiotemporal prediction models of cetacean habitats in the mid-western North Atlantic Ocean (from Cape Hatteras, North Carolina, USA to Nova Scotia, Canada). Mar Mamm Sci 18:920-939

Hastie TJ, Tibshirani RJ (1990) Generalized additive models, Vol 43. Chapman \& Hall/CRC, Boca Raton, FL

Haury LR, McGowan JA, Wiebe PH (1978) Patterns and processes in the time-space scales of plankton distributions. In: Steele JH (ed) Spatial pattern in plankton communities. Plenum Press, New York, p 277-327

Heinemann D, Hunt GL, Everson I (1989) Relationships between the distributions of marine avian predators and their prey, Euphausia superba, in Bransfield Strait and southern Drake Passage, Antarctica. Mar Ecol Prog Ser 58:3-16

Hunt GL (1991) Marine ecology of seabirds in polar oceans. Am Zool 31:131-142
Hunt GL, Heinemann D, Everson I (1992) Distributions and predator-prey interactions of macaroni penguins, Antarctic fur seals, and Antarctic krill near Bird Island, South Georgia. Mar Ecol Prog Ser 86:15-30

Jaquet N, Whitehead H (1996) Scale-dependent correlation of sperm whale distribution with environmental features and productivity in the South Pacific. Mar Ecol Prog Ser 135: $1-9$

Kinzey D, Olson P, Gerrodette T (2000) Marine mammal data collection procedures on research ship line-transect surveys by the Southwest Fisheries Science Center. Administrative Report No. LJ-00-08, Southwest Fisheries Science Center, La Jolla, CA

Levin SA (1992) The problem of pattern and scale in ecology. Ecology 73:1943-1967

> Logerwell EA, Hargreaves NB (1996) The distribution of sea birds relative to their fish prey off Vancouver Island: opposing results at large and small spatial scales. Fish Oceanogr 5:163-175

> Logerwell EA, Hewitt RP, Demer DA (1998) Scale-dependent spatial variance patterns and correlations of seabirds and prey in the southeastern Bering Sea as revealed by spectral analysis. Ecography 21:212-223

McCullagh P, Nelder JA (1989) Generalized linear models, Vol 37. Chapman \& Hall, New York

Murphy EJ, Morris DJ, Watkins JL, Priddle J (1988) Scales of interactions between Antarctic krill and the environment. In: Sahrhage D (ed) Antarctic Ocean resources variability. Springer-Verlag, Berlin, p 120-130

Piatt JF (1990) The aggregative response of common murres and Atlantic puffins to schools of capelin. Stud Avian Biol 14:36-51

Pinaud D, Weimerskirch H (2005) Scale-dependent habitat use in a long-ranging central place predator. J Anim Ecol 74:852-863

> Redfern JV, Ferguson MC, Becker EA, Hyrenbach KD and others (2006) Techniques for cetacean-habitat modeling: a review. Mar Ecol Prog Ser 310:271-295

Reilly SB (1990) Seasonal changes in distribution and habitat differences among dolphins in the eastern tropical Pacific. Mar Ecol Prog Ser 66:1-11

Reilly SB, Fiedler PC (1994) Interannual variablity of dolphin habitats in the eastern tropical Pacific. I: research vessel surveys 1986-1990. Fish Bull (Wash DC) 92:434-450

Reilly SB, Fiedler PC, Gerrodette T, Ballance LT, Pitman RL, Borberg JM, Holland RC (2002) Eastern tropical Pacific dolphin habitats - interannual variability 1986-2000. Report No. LJ-02-21, NOAA, National Marine Fisheries Service, Southwest Fisheries Science Center, La Jolla, CA

Schneider DC, Piatt JF (1986) Scale-dependent correlation of seabirds with schooling fish in a coastal ecosystem. Mar Ecol Prog Ser 32:237-246

Smith RJ (1993) Logarithmic transformation bias in allometry. Am J Phys Anthropol 90:215-228

> Smith WHF, Sandwell DT (1997) Global sea floor topography from satellite altimetry and ship depth soundings. Science 277:1956-1962

Wade PR, Gerrodette T (1993) Estimates of cetacean abundance and distribution in the eastern tropical Pacific. Rep Int Whaling Comm 43:477-493

Wiens JA (1989) Spatial scaling in ecology. Funct Ecol 3: 385-397

Wyrtki K (1966) Oceanography of the eastern equatorial Pacific ocean. Oceanogr Mar Biol Annu Rev 4:33-68

Wyrtki K (1967) Circulation and water masses in the eastern equatorial Pacific ocean. Int J Oceanogr Limnol 1:117-147 